\title{
Stress-induced martensitic transformation in polycrystalline alloys
}

\author{
Etienne Patoor ${ }^{1}$, Denis Entemeyer ${ }^{1}$, André Eberhardt $^{1}$, Marcel Berveiller $^{1}$ \\ ${ }^{1}$ LPMM (Laboratoire de Physique et Mécanique des Matériaux) Université de Metz / CNRS, Ile du Saulcy, 57045 Metz, France
}

\begin{abstract}
Modern scale transition methods developed in mechanics of materials these last years are successfully applied to model the particular behavior exhibited by shape memory alloys. Starting from a local kinematical analysis based on crystallographic considerations and determining the thermodynamical forces associated to the martensitic phase transformation local relationships are determined using the self-consistent approximation. This framework is applied to simulate different loading conditions using mechanical or thermal loading paths with uniaxial or multiaxial conditions. Results such obtained are compared with experimental results.
\end{abstract}

\section{Introduction}

Shape memory alloys (SMA) are materials capable to undergo very large reversible strains under mechanical stress or variations of temperature [1]. Such behaviours are due to the martensitic transformation wich can appear with different orientation (plates or variants). The crystallographic study of the transformation [2] has allowed to propose a relationship between the transformation deformation of a variant and its characteristics that are :

- the normal (n) to the habit plane between the austenite not transformed and the variant of martensite;

- the direction of transformation (m);

- the amplitude of deformation $(g)$ in the direction $\boldsymbol{m}$.

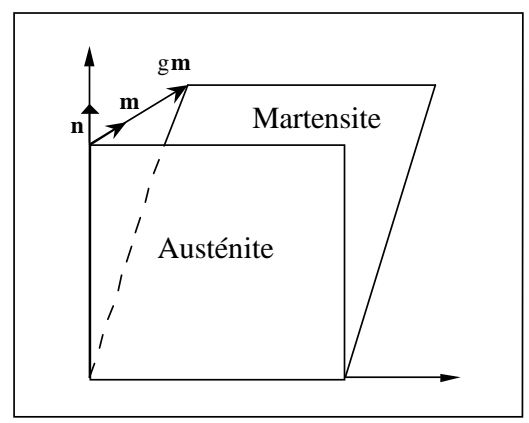

$$
\dot{\varepsilon}^{T}=\frac{g}{2}(n \otimes m) \dot{f}=g R \dot{f}
$$

$\dot{f}$ is the rate of the volumic fraction of the variant considered

Figure 1: Transformation of a volume element and strain associated to the transformation 
E. Patoor, D. Entemeyer, A. Eberhardt, M. Berveiller. Stress-induced martensitic transformation in polycrystalline alloys. Journal of Applied Mathematics and Mechanics / Zeitschrift für Angewandte Mathematik und Mechanik, Wiley-VCH Verlag, 2000, Short Communications in Mathematics and Mechanics Sections 1-7, University of Metz, France April 12-16, 1999, 80 (S2), pp.443-444.

$\langle 10.1002 /$ zamm.20000801493〉

\section{Modelling}

In a first time, a micromechanical approach based on the physical mechanisms responsible of the behavior (variants of martensite) is necessary to determine microscopic properties. A kinematic study gives the total strain of the single crystal and a potential (complementary free energy) allows to calculate evolution of volumic fractions of variants. Finally we determine microscopic properties according to the microstructure: $l(r)$ and $m(r)=$ function(microstructure) [3].

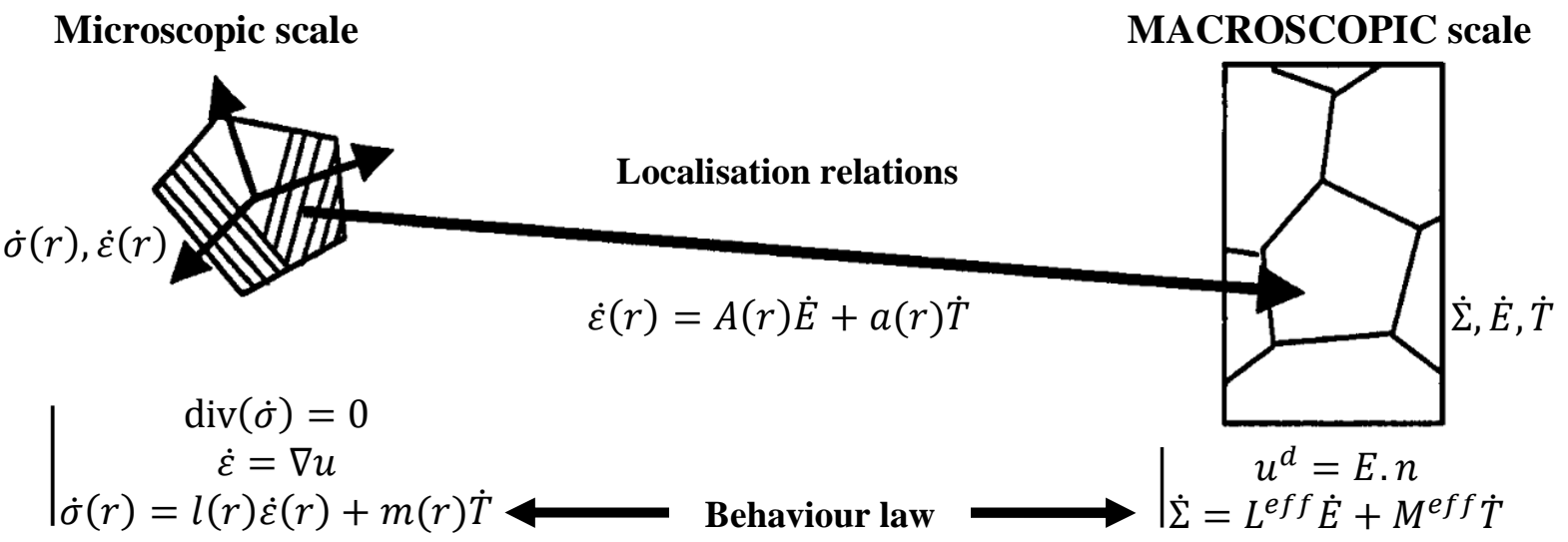

Figure 2: Principles of the self-consistent method

In a second time, the handwriting and the resolution of a thermomechanical integral equation allow to completely define the macroscopic behavior from microscopic properties. In addition, the utilization of the Green theory allows to take into account interactions between the different grains. By assuming properties are uniform in grains, we obtain [4]:

$$
\left\{\begin{array} { c } 
{ L ^ { e f f } = \sum _ { \text { grain I } } l ^ { I } A ^ { I } f ^ { I } } \\
{ M ^ { e f f } = \sum _ { \text { grain I } } ( m ^ { I } - l ^ { I } a ^ { I } ) f ^ { I } }
\end{array} \quad \text { with } \quad \left\{\begin{array}{l}
A^{I}=\left[\mathrm{I}-T^{I I}\left(l^{I}-L^{e f f}\right)\right]^{-1} \\
a^{I}=-A^{I} T^{I I}\left(m^{I}-m^{e f f}\right)
\end{array}\right.\right.
$$

\section{Results}

Numerical and experimental results are applied on a $\mathrm{Cu}-\mathrm{Al}-\mathrm{Be}$ SMA [4]. The polycrystal is described by 100 grains with their crystallographic orientation randomly chosen in order to don't induce a texture effect (figure 3). 

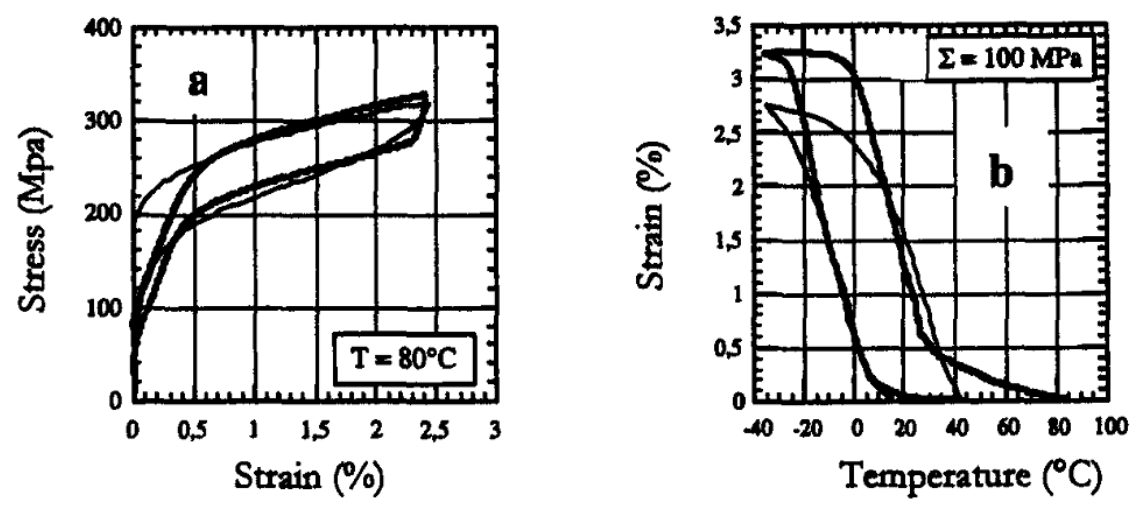

Figure 3: Numerical $($ ) and experimental $(\longrightarrow$ results for a $\mathrm{Cu}-\mathrm{Al}-\mathrm{Be}$ Alloy during a tensile test at $\mathrm{T}=80^{\circ} \mathrm{C}$ (a) and a cooling with an applied stress equal to $100 \mathrm{MPa}(\mathbf{b})$.

The advantage of the model is that it's possible to numerically draw the evolution of some data as volumic fractions of variants. The figure 4 shows this evolution in the same grain for 4 different loadings. Two tensile test are performed at $\mathrm{T}=140^{\circ} \mathrm{C}(\mathbf{a})$ and at $\mathrm{T}=41^{\circ} \mathrm{C}(\mathbf{b})$ : they show that only two variants persist at the end of the transformation, these variants are the best oriented variants. On the contrary for the cooling with low applied stress (d), the number of variant increases (some grains have until 16 variants appearing) and we can note the appearance of a self-accommodating group (variants 5, 6, 7 and 8). These results are confirmed by crystallographical observations.
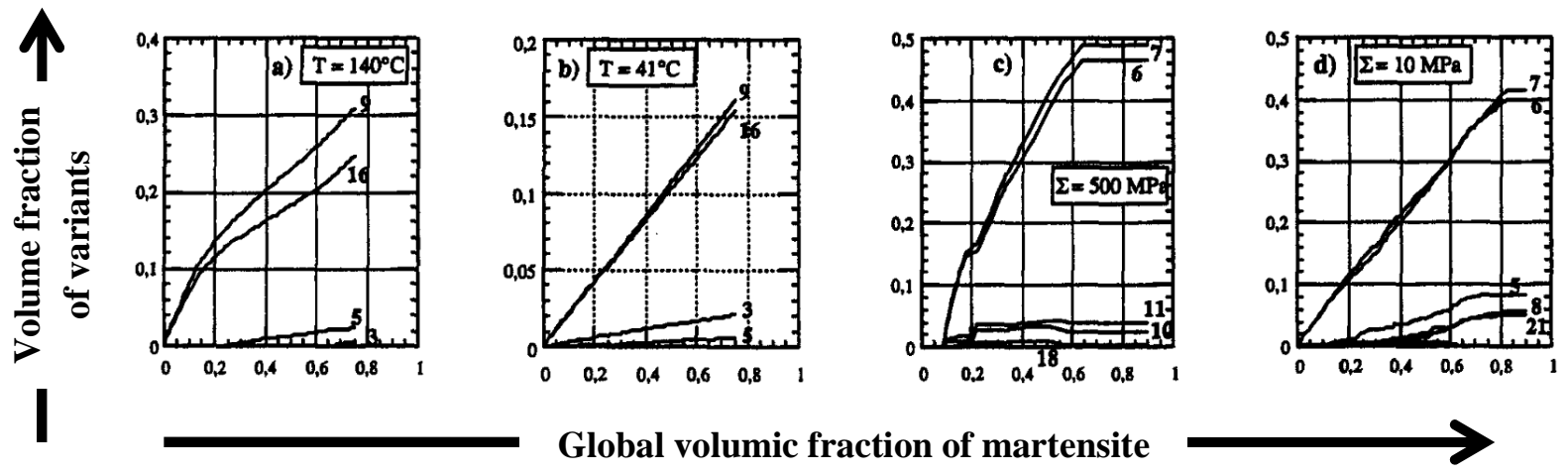

Global volumic fraction of martensite

Figure 4: Evolution of variants during a tensile test at $\mathrm{T}=140^{\circ} \mathrm{C}(\mathbf{a}), \mathrm{T}=41^{\circ} \mathrm{C}(\mathbf{b})$ and a cooling with an applied stress equal to $500 \mathrm{MPa}(\mathbf{c})$ and $10 \mathrm{MPa}(\mathbf{d})$.

\section{References}

1. E. PATOOR; M. BERVEILLER : Las Alliages à Mémoire de Forme, Ed. HERMES, 1985

2. M.S. WESCHLER, D.S. LIEBERMANN, T.A. READ : On the theory of the formation of martensite, Trans. AIME, 197, 1953, p. 1503-1515

3. N. SIREDEY, E. PATOOR, M. BERVEILLER, A. EBERHARDT : Constitutive Equations for Polycrystalline Thermoelastic Shape Memory Alloys - Part I) Intragranular interactions and behavior of the grain, I.J.S.S., to be published

4. D. ENTEMEYER : Modélisation micromécanique du comportement thermomécanique des alliages à mémoire de forme, Thèse, Université de Metz, 1996 